\title{
Functional electrical stimulation cycling strategies tested during preparation for the First Cybathlon Competition - a practical report from team ENS de Lyon
}

\author{
Amine Metani (1), Lana Popović-Maneski (2), Sebastien Mateo (1,3,4), Laura Lemahieu \\ (1), Vance Bergeron (1) \\ (1) École Normale Supérieure de Lyon, CNRS UMR 5672, Lyon, France; (2) Institute of \\ Technical Sciences of the Serbian Academy of Sciences and Arts, Belgrade, Serbia; (3) \\ Université de Lyon, Université de Lyon 1, INSERM U1028, CNRS UMR 5292, Lyon \\ Neuroscience Research Center, ImpAct Team, Lyon, France; (4) Hospices Civils de Lyon, \\ Hopital Henry Gabrielle, Plateforme Mouvement et Handicap, Lyon, France
}

This article is distributed under the terms of the Creative Commons Attribution Noncommercial License (CC BY-NC 4.0) which permits any noncommercial use, distribution, and reproduction in any medium, provided the original author(s) and source are credited.

\begin{abstract}
Whether it is from the patient's or the physical therapist's point of view, FES cycling can be considered either as a recreational activity, or an engaging rehabilitation tool. In both cases, it keeps patients with lower-limb paralysis motivated to sustain a regular physical activity. Thus, it is not surprising that it was selected as one of the six disciplines of the first Cybathlon competition held on October 8, 2016. However, many unresolved issues prevent FES cycling from being an activity practiced outdoors on a daily basis; such as, low power production, rapid muscle fatigue, precise electrode positioning, lack of systematic procedures to determine stimulation patterns, and the difficulty of transferring disabled riders from their wheelchair to the tricycle. This article documents the challenges we faced during preparation for the Cybathlon 2016 FES cycling race, and provides results obtained during different phases of the process. A particular specificity of our team was that, unlike most other teams where pilots were mainly paraplegic, both the primary and backup pilots for team ENS de Lyon are C6/C7 tetraplegics, with neither voluntary control of their abdominal muscles nor hand grip, and only partial use of their arms.
\end{abstract}

Key Words: FES-cycling; Cybathlon; Spinal Cord Injury

Eur J Transl Myol 27 (4): 279-288

The first cybernetic Olympic games, namely the "Cybathlon", 1 took place in Zurich on October 2016. These games included, among five other disciplines, a Functional Electrical Stimulation (FES) cycling race. FES is a method of delivering bursts of short electrical pulses to nerves and muscles that elicit muscle contractions and produce functional movements in paralyzed limbs. ${ }^{2}$ ] It can be used on several muscle groups in a defined order to produce cyclic leg movements, which enables the rider to pedal an adapted bicycle or tricycle. Because it is a recreational activity, FES cycling is a convenient rehabilitation tool often recommended for patients with motor disabilities, ${ }^{3,4}$ that keeps them motivated to sustain a regular physical activity. In the particular case of spinal cord injured patients, extensive literature data shows that lower-limb FES reduces blood pressure and bone loss, ${ }^{5}$ spasticity, ${ }^{6}$ increases muscle mass, ${ }^{7}$ and therefore reduces the incidence of pressure sores. ${ }^{8}$ Notably, this results in a general decrease in the incidence of secondary diseases and poor health conditions due to the sedentary lifestyle imposed by paralysis. In addition, psychological barriers developed in some paralyzed individuals and loss of social interactions can be reduced. For instance, outdoor FES cycling enables disabled individuals to ride together and with other non-handicapped groups. Only pilots with a spinal cord injury (SCI) resulting in complete lower limb muscle paralysis, using nonmotorized systems, were allowed to participate in the FES cycling competition at the 2016 Cybathlon. To prepare for the competition, the teams needed to develop effective muscle stimulation strategies, complemented by appropriate training of the pilots that enabled them to build muscle strength and increase their endurance. Due to unfavorable biomechanics, weakened muscles and the fact that transcutaneous electrical stimulation can partially activate only superficial 


\begin{tabular}{|c|c|c|}
\hline \multicolumn{3}{|c|}{ Table 1. Details for main and backup pilots } \\
\hline & Main Pilot & Backup pilot \\
\hline Inclusion criteria & $\begin{array}{l}\text { motivated tetraplegic individual, } \\
\text { involved in a long-term training } \\
\text { on FES cycling }\end{array}$ & $\begin{array}{l}\text { motivated tetraplegic individual, } \\
\text { involved in a long-term training } \\
\text { on FES cycling }\end{array}$ \\
\hline Pilot selection & $\begin{array}{l}\text { Motivation and interest in cycling } \\
\text { (cyclist before SCI), efficient FES } \\
\text { on lower limb muscles }\end{array}$ & $\begin{array}{l}\text { Motivation and interest in cycling } \\
\text { (cyclist before SCI), efficient FES } \\
\text { on lower limb muscles }\end{array}$ \\
\hline Level of injury & $\begin{array}{l}\text { ASIA motor } \\
\text { C6 Right, C7 left } \\
\text { AIS B }\end{array}$ & $\begin{array}{l}\text { ASIA motor } \\
\text { C6 Right, C7 left } \\
\text { AIS B }\end{array}$ \\
\hline Year of injury & 2013 & 2013 \\
\hline Daily activities & $\begin{array}{l}\text { FES Cycling on RT300 at least } \\
\text { once a week for one hour. }\end{array}$ & $\begin{array}{l}\text { FES Cycling on RT300 at least } \\
\text { once a week for one hour. }\end{array}$ \\
\hline Height $(\mathrm{cm})$ & 182 & 181 \\
\hline Weight $(\mathrm{kg})$ & 75 & 72 \\
\hline Body Mass Index (mass/height ${ }^{2}$ ) & 21.6 & 21.6 \\
\hline
\end{tabular}

muscles, the mechanical power produced by a SCI pilot is typically ten times lower to that of an average healthy cyclist (e.g. 10W versus 100W). In addition, rapid muscle fatigue occurs due to the non-physiological recruitment of muscle fibers; unlike natural muscle contraction (starting with asynchronous activation of slow then fast twitch muscle fibers), FES-induced muscle contraction involves mainly type II fibers (fast twitch) with a higher activation rate and instantaneous recruitment of all available fibers. ${ }^{9,10}$ Moreover, deep muscles like the hip flexors, which pull the pedals back toward the pilot after the leg has been flexed, are difficult to reach using transcutaneous stimulation. Consequentially part of the pedal rotation is problematic to complete, particularly when the pedal is positioned in the so-called "dead spot" (a position in which one leg is fully extended and the other fully flexed). Difficulties in overcoming this position also contribute to the low power outputs observed. In summary, early muscle fatigue, insufficient selectivity and the "dead spot" lead to slow speeds (approximately $10 \mathrm{~km} / \mathrm{h}$ ) and rather short distances covered by non motor-assisted FES cycling. During the 2016 Cybathlon, FES cycling pilots manually controlled the amount of stimulation they received, which allowed them to regulate their speed in relation to their endurance. The FES cycling race was a fixed distance race of 750 meters on a flat indoor track with a launching ramp to propel the participants from the stationary starting position. The maximum time limit to complete the course was set to 8 minutes. Only 5 teams out of 11 were able to finish the distance in the required time during qualifications, and the fastest nonimplanted FES cycling pilot completed 750 meters in 3 m $59 \mathrm{~s}(11.3 \mathrm{~km} / \mathrm{h}$ average $)$.
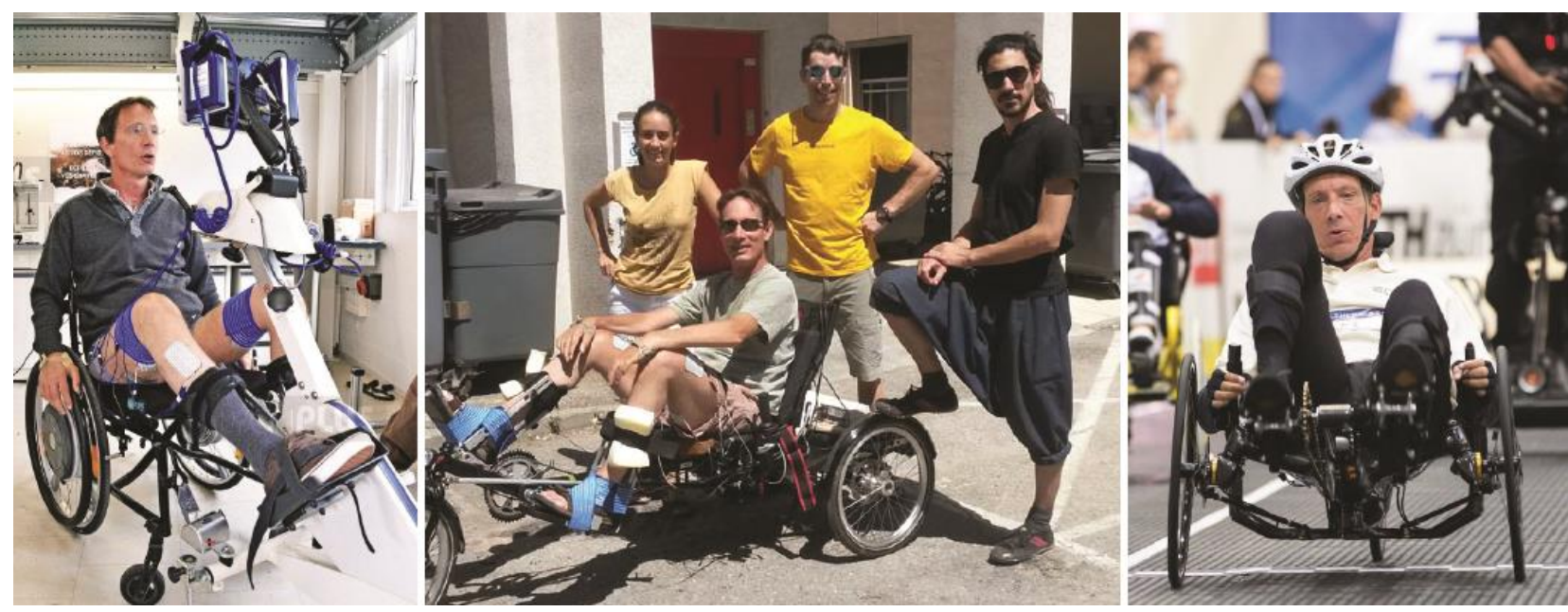

Fig 1. Training devices. Left: RT300 (Restorative Therapies, US); middle: HASE trike with Rehastim 1 stimulator (Hasomed, Germany); Right: competing trike: Carbontrikes Race SL (Carbontrikes, Sweden) equipped with two Rehastim 1 stimulators. 


Table 2. Timings for each competition rehearsal
\begin{tabular}{|c|c|c|}
\hline Session & Distance $(m)$ & Timing \\
\hline $\mathbf{1}$ & $\mathbf{7 5 0}$ & $\mathbf{0 6 : 1 5}$ \\
\hline 1 & 250 & $01: 23$ \\
\hline 1 & 250 & $01: 22$ \\
\hline $\mathbf{2}$ & $\mathbf{7 5 0}$ & $\mathbf{1 2 : 0 0}$ \\
\hline 2 & 250 & $2: 07$ \\
\hline 2 & 250 & $1: 50$ \\
\hline 2 & 250 & $2: 00$ \\
\hline $\mathbf{3}$ & $\mathbf{7 5 0}$ & $\mathbf{8 : 1 8}$ \\
\hline 3 & 250 & $1: 32$ \\
\hline 3 & 250 & $1: 45$ \\
\hline 3 & 250 & $1: 47$ \\
\hline $\mathbf{4}$ & $\mathbf{7 5 0}$ & $\mathbf{6 : 5 1}$ \\
\hline 4 & 250 & $1: 28$ \\
\hline $\mathbf{5}$ & $\mathbf{7 5 0}$ & $\mathbf{6 : 5 5}$ \\
\hline 5 & 250 & $1: 38$ \\
\hline 5 & 250 & $2: 08$ \\
\hline
\end{tabular}

In this article, we will report on the devices and strategies tested by team ENS de Lyon prior to our participation in the Cybathlon.

\section{Pilot Details}

Primary and backup pilot characteristics are listed in Table 1. The primary pilot was aged 54 and backup pilot 52 years old. The SCI for both pilots is at the C6\C7 cervical level and both were avid bicyclists (7k$14 \mathrm{k}$ per year) and in excellent physical shape when their bicycle accidents occurred in 2013. Following the accidents both pilots remained as physically active as possible and began training for the FES cycling race in the fall of 2015 (Figure 1).

\section{Physical Preparation}

The first three phases of the pilots' physical preparation was carried out using a RT300 stationary FES indoor trainer (Restorative Therapies, USA). The fourth (and final phase) was completed on recumbent FES trikes. Many factors influenced this choice. Initially in the winter months, the indoor RT300 trainer is more convenient to use compared to an outdoor trike due to the adverse weather conditions. Furthermore, a transfer is not required (the pilot can directly attach his wheelchair to the RT300 device), and it facilitated measurements of physiological parameters and monitoring of the pilots' status. The RT300 utilizes two dedicated electrical stimulators with 6 channels each. In addition to the usual quadriceps, hamstrings and glutei, the tibialis anterior, abdominals and erector spinae back muscles can also be stimulated when training on the RT300. Training was carried out with this device by specifying a resistant torque (up to $20.75 \mathrm{Nm}$ ), and rpm (up to 55rpm) for which the devices' control system will target by modulating the stimulation current intensity within pre-defined ranges by the user. A typical scenario to proceed with for a 1-hour long training session consisted of setting the resistant torque and the cycling rpm such that the device started at approximately $50 \%$ of its' maximum stimulation intensity to maintain a smooth pedaling cadence by the rider. As the training proceeds, stimulation intensity automatically increases to compensate for muscle fatigue and maintain the targeted performance. Using this procedure in our training sessions, the rpm typically varied between 30 and $40 \mathrm{rpm}$, while the resisting torque was not systematically monitored. Instead the torque was adjusted to maximize the pilots' watt (watt = torque $[\mathrm{Nm}] \mathrm{x}$ angular speed $[\mathrm{rpm}]$ ) output in such a way that the maximum stimulation intensity was never reached within the one hour training period. Maximum intensity was set at $140 \mathrm{~mA}$ for quadriceps and glutei, and $100 \mathrm{~mA}$ for the hamstrings. Based on recommendations from physical therapists working with Restorative Therapies, the stimulation pulse width was set at $350 \mu \mathrm{s}$ for the quadriceps and hamstrings, and $250 \mu \mathrm{s}$ for glutei. The other muscle groups weren't systematically used, and if they were, the maximum intensity and the pulse width varied, and were not monitored. The choice to stimulate other core muscles such as the stomach and lower back was left to the pilots' discretion. We note that no significant performance advantages were seen when stimulating these supplementary muscles. The stimulation frequency was empirically set at $40 \mathrm{~Hz}$ for all channels following the observation that less than $20 \mathrm{~Hz}$ did not result in fused muscle contraction, ${ }^{11}$ and that we were not able to measure any substantial increase in watt output with frequencies higher than $40 \mathrm{~Hz}$. Using $30 \mathrm{~Hz}$ 


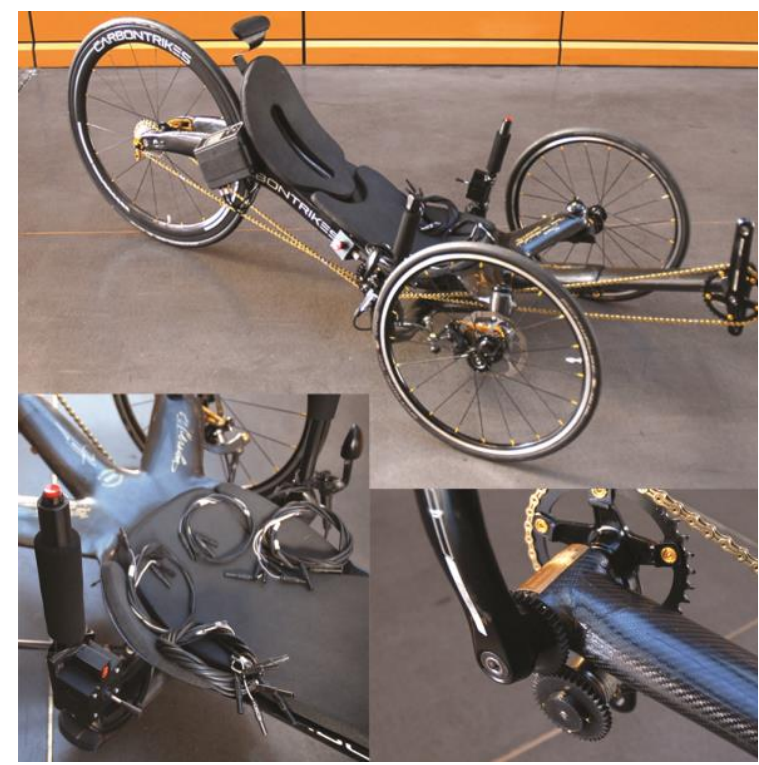

Fig 2. General view of the Tetratrike with details on the throttle, brake and encoder's gears. In the top figure, the stimulators are fixed on opposite sides of the frame behind the seat. In the left bottom angle is a handle with a red push button on top for an instantaneous stop of the stimulation, and a joystick with a display for changing the intensity of stimulation in discrete steps by a simple push of the joystick downwards. On the other side of the seat is the handle brake (oval shaped). In the bottom left image, the reader can also observe dedication signatures from Eddie Merckx, Raymond Poulidor, and JeanChirstophe Peraud, all retired Tour de France champions.

may reduce muscle fatigue at the expense of lower force production, however, it also introduces the possibility of inducing large muscle contraction ripples (twitch) as some motor units stop firing due to fatigue. Hence, we decided to proceed with $40 \mathrm{~Hz}$ to produce more initial power and avoid potential problems associated with the above-mentioned ripple. That said, it would be of interest to further systematically study the influence of stimulation frequency on stimulation outcomes such as isokinetic force and muscle fatigue.

\section{Muscle Building}

The first phase of training started one year before the Cybathlon competition and targeted muscle development by kinetic training with the RT300. Target mechanical power output and resistant torque where set so as to start the 1-hour session at $50-60 \%$ of the maximum current intensity, and finish at the $70 \%$ level in the last ten minutes of the training session. Pilots trained once a week, for a total of 24 sessions.
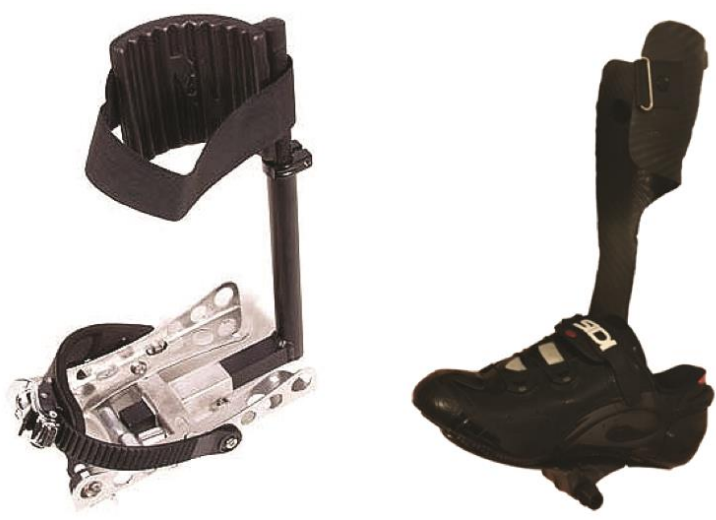

Fig 3. Pedal orthoses: Berkelbike aluminum (left) and custom-made carbon (right).

Power production and muscle endurance

The second phase began 6 months before the event and consisted of 1-hour sessions of kinetic training with the RT300, starting at $50-60 \%$ of maximum current intensity, and finishing at $90 \%$ in the last ten minutes. Similar to the first training phase, pilots trained once a week, totaling 24 sessions.

\subsection{Power production and faster recovery}

The third phase of training started 2 months before the competition, and consisted of 1-hour long training sessions. Again, using the RT300, these training sessions where composed of interval training using the following sequence: first a 10 -minutes warm-up at $60 \%$ intensity, followed by 6 minutes at $80 \%$, and then 2 minutes of recovery at $50 \%$. Pilots trained once or twice a week, for a total of 8 sessions.

\subsection{Rehearsals}

The fourth and last phase of training started two weeks before the event. This is the only phase where an actual recumbent trike was extensively used. It consisted of 45-minutes sessions simulating the race conditions in an indoor gymnasium. Nine laps around the gymnasium where required to complete the distance of the race $(750 \mathrm{~m})$. Each session lasted one hour and began with two laps of warm-up, followed by a simulation of the race, including the race starting block from a launching ramp that was designed to meet the competition regulations. We timed the duration of each lap to compute the average trike velocity. Interestingly, the second lap was the fastest in all trials. In the fourth lap, there was a substantial increase in time due to muscle fatigue and that also corresponded to the time when the pilots usually increased the level of stimulation for the first time in the race. Pilots performed a total of 5 sessions. Pilots had to rest every other day because we noticed that two consecutive days of training resulted in faster fatigue and pilots were unable to finish $750 \mathrm{~m}$ in less than 8 min (Table 2). 

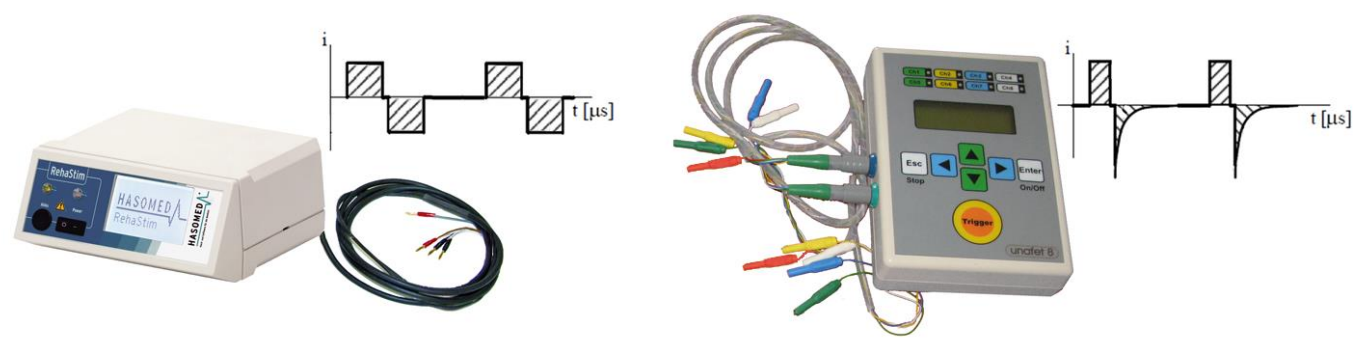

Fig 4. Stimulators and their generated current pulses. Rehastim 1 (left) and Unafet (right).

\section{Tricycle Information}

We successively used three different trikes in preparation for the race: BerkelBike Pro (BerkelBike B.V., Netherlands), ${ }^{12}$ Rehabike (Hasomed GmbH, Germany), ${ }^{13}$ and Carbontrikes Race SL (Carbontrikes, Sweden). ${ }^{14}$ The first two were commercially available FES trikes; the third one, which we named "TetraTrike" was a custom made mono-bloc carbon recumbent trike that we equipped with in-house FES equipment. The TetraTrike was used for the competition (Figure 1).

\section{BerkelBike Pro}

The BerkelBike pro is a hybrid trike which combines a hand cycle with a delta designed recumbent trike (one front wheel, two back wheels) driven by both the pilot's arms and legs. The hand crank and foot pedals are connected through a free-wheel making it possible to pedal the trike with the legs only and to use the hand crank simply as a handle bar for steering. As soon as the hand crank is engaged with force from the arms, the pedals move simultaneously with a fixed gear ratio between the two. With this hybrid system, movement of the legs can thus be supported by power from the arms and shoulder, which is very convenient for paraplegics, because it allows them to exercise both upper and lower limbs at the same time. In addition, the BerkelBike allows for easy transfer because the height of the seat corresponds to that of a standard wheelchair, which is substantially higher than that of a typical recumbent trike. However, one drawback of this convenience is a partial loss of stability due to the relatively high center of gravity. We do also note that the Cybathlon rules require power generation strictly from the legs, hence, the hand crank can only be used in the competition for steering. Stimulation is provided by one dedicated six channel stimulator that can be adjusted for tailoring the stimulation pattern for each pilot. Modulating the current intensity controls this stimulator.

\section{Rehabike}

The Rehabike was the first commercial FES trike on the market and was produced by Hasomed $\mathrm{GmbH}$, in Germany. This delta recumbent trike, which is no longer in production, was developed in collaboration with the University of Glasgow and the Max Planck Institute in Magdeburg. It is based on a first generation Lepus bike frame (Hase Bikes, Germany), and uses a Rehastim 1 stimulator (Hasomed, Germany) in a specific mode referred to as "cycle mode", which is designed by the manufacturer to allow for simplified use in FES-cycling applications. ${ }^{15}$ The cyclist uses a throttle to control the stimulation intensity and thus the speed of the trike.

\section{TetraTrike}

For our development of a competitive FES trike we collaborated with the company Carbontrikes, in Bandhagen, Sweden, who produce the lightest and fastest recumbent trikes on the market. A custom built Carbontrikes Race SL tadpole recumbent trike (two front wheels, one back wheel) was used as the basis for our TetraTrike. It has a $100 \%$ carbon mono-bloc frame and the following unique design features were incorporated:

a) The battery for the DI2 Shimano electronic gear system is mounted on the inside of the hatch in the seat where it is easy to reach for charging. We have reprogrammed the DI2-system to use only the rear derailleur and a gear shifter with larger than standard buttons that are easier to reach and use by motordisabled individuals,

b) The wheels are unique, and likely some of the lightest ever used on a trike, with far fewer spokes (e.g. 20) than standard. The front wheels have a rather large diameter $(451 \mathrm{~mm}$ instead of the $406 \mathrm{~mm}$ standard) to minimize the rolling resistance. To avoid changes to the standard steering system the wheels are asymmetrical spoked to compensate for the larger wheels. Otherwise the wheel spokes would interfere with steering the trike.

c) The chain routing is optimized for maximum efficiency and to allow using the trike without a free wheel. The chain idler is significantly larger than the standard, and there is one on the return chain instead of a tube, unlike that normally used on recumbent trikes, and the chain guide wheels are mounted in a leaning position to avoid side loads.

d) The 110 BCD (Bolt Circle Diameter) crankset used is a lightweight square type with a long bottom bracket $(122,5 \mathrm{~mm})$. A $34 \mathrm{~T}$ (Tooth) single chainring is mounted and we also have an additional lightweigh $46 \mathrm{~T}$ chainring that uses larger sprockets to maximize the efficiency in the drive train if desired. 
Table 3. Initial and final stimulation patterns. Zero angle is when the crank arm is positioned horizontally, and the leg flexed.

\begin{tabular}{|l|c|c|c|}
\hline \multicolumn{1}{|c|}{ Pattern } & $\begin{array}{c}\text { Quadriceps } \\
\left.\text { (Back muscles }-180^{\circ}\right)\end{array}$ & Hamstrings & Glutei \\
\hline TUM minimum & $15-140$ & $110-250$ & $140-210$ \\
\hline TUM average sym. & $15-156$ & $106-272$ & $109-259$ \\
\hline TUM avg. early butt. & $16-157$ & $106-272$ & $73-263$ \\
\hline Mueller symmetrical & $10-163$ & $78-266$ & $73-237$ \\
\hline Kaiser symmetrical & $3-156$ & $89-269$ & $157-325$ \\
\hline Hunt et al. 1 & $10-110$ & $123-200$ & $45-135$ \\
\hline Hunt et al. 2 & $355-125$ & $108-215$ & $45-135$ \\
\hline Main pilot final & $\mathbf{1 0 - 1 6 0}$ & $\mathbf{1 1 0 - 2 5 0}$ & $\mathbf{5 0 - 1 8 0}$ \\
\hline Backup pilot final & $\mathbf{1 5 - 1 8 0}$ & $\mathbf{1 1 0 - 2 5 0}$ & $\mathbf{1 4 0 - 2 1 0}$ \\
\hline
\end{tabular}

e) The frame and handle bar are not painted in the traditional way but instead the manufacture has applied a thin, superlight, special top coat epoxy system, adding only 5 grams to the entire frame. Also, the lay-up of the carbon fiber sheets in the frame and boom are optimized to provide minimum weight instead of favoring the trike's cosmetic appeal.

The weight of the trike out of the box was $11.5 \mathrm{~kg}$, and the fully equipped trike with stimulators, controller, electrodes, cables and sensors is $13 \mathrm{~kg}$.

We made several modifications to the TetraTrike (Figure 2). First, since the pilots' hip flexor muscles, which are normally used by healthy pilots to overcome the pedal "dead spot", are not accessible using our transcutaneous stimulation, we attempted a mechanical modification to resolve this problem. Our first attempt was to consider an asymmetric shaped chainring. The rationale for this choice was the hypothesis that the moment arm would change throughout the pedal stroke and if properly adjusted could compensate for the lack of specific muscle stimulation. A commercially available O-symetric chainring was tested, ${ }^{16}$ however, no substantial improvement was observed and it was replaced by the original chainring provided by the manufacturer. We then removed the derailleur and shifter to modify the sprocket wheel in order to create a fixed-gear system. With this system, the momentum of the trike and rider entrains the legs smoothly through the dead spot. Using the fixed gear we achieve significant increases in pedal efficiency in agreement with that observed by Szecs et.al. ${ }^{17}$ This configuration solved the dead spot issue for both of our pilots.

An analogue rotary 5V-powered encoder (Megatron, France, 36A MSL RCS), was used to provide the position of the pedals, which was subsequently sent to a Hasomed Rehastim 1 stimulator to actuate and engage the appropriate muscle groups needed to propel the trike. Furthermore, as speed was usually low (below $10 \mathrm{~km} / \mathrm{h}$ ), we retained only one disc brake on the right front wheel (Shimano XT, Hydraulic disc, $160 \mathrm{~mm}$ ) so as to reduce overall weight of the trike. Since our pilots have no hand-grasp function, we also modified the brake handle so the pilot can press down on the brake lever instead of squeezing it to engage the brake and stop the trike. Measured from a horizontal line, the seat angle was set at $28^{\circ}$. The two front wheels and hand handlebars made it impossible for the pilots (incomplete tetraplegics) to transfer from their wheelchair into the trike without external assistance.

\section{Pedal Orthoses}

We designed and constructed different types of carbonfiber foot orthoses combined with standard professional bike shoes and quick release pedals (Figure 3, right). However, none of the systems we developed provided
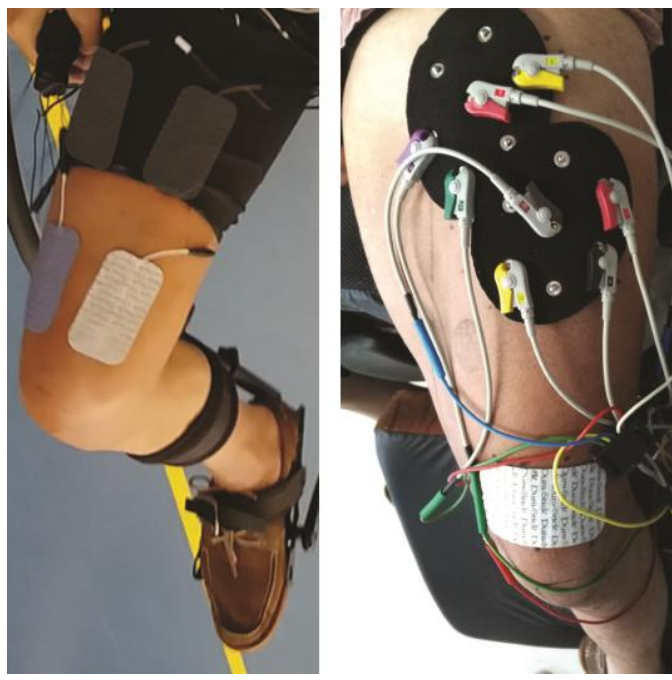

Fig 5. Positions of the electrodes used in Cybathlon (left) and for fatigue reduction tests (right). 

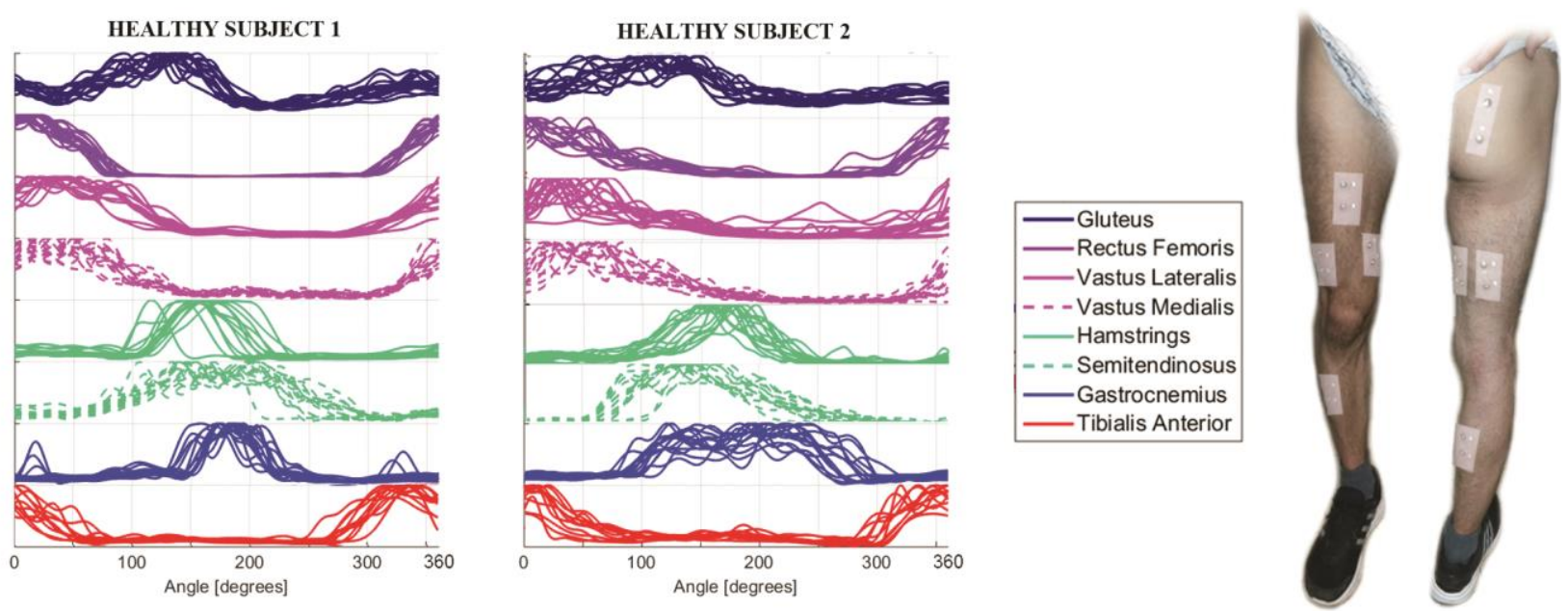

Fig 6. Normalized EMG recordings from two healthy subjects while riding the Tetratrike. Superimposed lines with the same color represent multiple turns of pedals in relation to the crank arm angle. Zero angle is when the crank arm is positioned horizontally, and the leg flexed.

satisfactory knee support to maintain the pilots leg in the sagittal plane, resulting in the pilots' legs frequently being ejected from the quick release pedals. Although our attempts have not been successful to date, we feel quick release pedals are better for safety, as they will release the pilots' foot if excessive torque in the nonsagittal plane builds up in the legs, which in principle could lead to leg fractures due to the low bone densities observed in SCI pilots. We eventually used commercially available pedals with a calf support (Figure 3, left) manufactured by HASE Bikes.

\section{Electrical Stimulation}

\section{Stimulators}

The BerkelBike Pro and RT300 used dedicated FES stimulators, whereas Rehabike came with a Hasomed Rehastim 1 stimulator, and the TetraTrike was supplied without a stimulator. For the latter, we used both Rehastim 1 and Unafet stimulators, both described in the following paragraphs (Figure 3 and 4).

\section{Hasomed Rehastim 1}

Hasomed Rehastim 1 is one of the most widely used neuro-muscular electrical stimulators in the field of functional electrical stimulation. It has eight separate bipolar channels, a Science mode that allows laptop control, and a Cycle mode. The latter works through a Cycle port that provides $5 \mathrm{~V}$ power to supply an analogue encoder, and receives the signal of the latter in order to trigger the stimulation pattern. It has a $10^{\circ}$ resolution for setting the start and stop pedal angles for stimulation, and $5 \mathrm{~mA}$ resolution for setting the intensity of the electrical pulses (up to $140 \mathrm{~mA}$ ). Unlike the BerkelBike and RT300 dedicated stimulators, the stimulation power is modulated via external control (throttle, button or similar) by changing the pulse width (from 0 to $500 \mu \mathrm{s}$ ), and not the current intensity. Current intensity is set for each channel before starting the stimulation. The current controlled pulses are rectangular biphasic and symmetrically compensated, and we used a frequency of $40 \mathrm{~Hz}$, while the maximum possible frequency with the Rehastim 1 is $50 \mathrm{~Hz}$.

In cycle mode, a specific communication port is used. This port provides a $5 \mathrm{~V}$ potential to supply power to the analogue rotary encoder that detects the position of the pedals, and to supply a potentiometer throttle used to modulate the pulse width. It also receives the signal from the encoder $\left(0-5 \mathrm{~V}\right.$ for $\left.0-360^{\circ}\right)$ and the throttle $(0$ $5 \mathrm{~V}$ for $0-500 \mu \mathrm{s})$. It turned out that our Rehastim 1 analogue input only detected voltages in the $0.1-4.9 \mathrm{~V}$ range, and in order to avoid measurement dead bands we had to tune the encoder's supply with appropriate voltage dividers. Likewise, a voltage signal of $5 \mathrm{~V}$ from the throttle did not result in a $500 \mu \mathrm{s}$ maximal pulse width, instead, the highest achievable width was limited to $490 \mu \mathrm{s}$.

\section{Unafet}

In some phases of our training, we used Unafet stimulators (Una systems, Serbia). ${ }^{18}$ They come with eight stimulation channels, divided into two outputs. Each of the two outputs are distributed with 5 cables, 4 cathodes and 1 anode. The unit has a $1 \mathrm{~mA}$ resolution for setting the current intensity, $1 \mathrm{~Hz}$ resolution for the frequency within the $10-100 \mathrm{~Hz}$ range and $10 \mu \mathrm{s}$ resolution for the pulse width in the range from 50-500 $\mu \mathrm{s}$. The current controlled pulses are rectangular biphasic, and exponentially compensated. It has digital input for on-off triggering of the stimulation, therefore we had to use it in conjunction with a microcontroller that acts as an $\mathrm{AD}$ converter changing analog inputs from the encoder for the digital trigger to the stimulator. The stimulator channel activation sequence can be programmed by setting the delay between different channels expressed in milliseconds. The channels are by default distributed equidistantly within one period of 

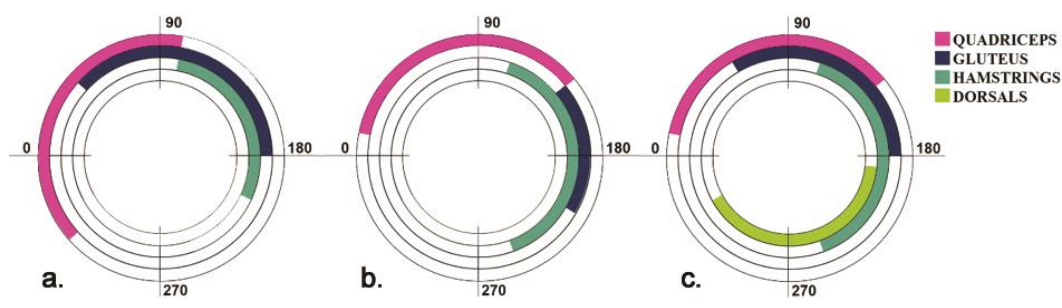

Fig 7. Stimulation patterns: pattern from healthy EMG (a), TUM minimum $(b)$ and Cybathlon pattern for main pilot (c). Zero angle is when the crank arm is positioned horizontally, and the leg flexed. Colored areas represent the angles in which the corresponding muscles were stimulated.

stimulation. For instance, if the stimulation frequency is $40 \mathrm{~Hz}$, each channel fires at $40 \mathrm{~Hz}$ but there is a time delay between consecutive channels equal to $25 / 8 \mathrm{~ms}$. This particularity allowed us to test an asynchronous distributed stimulation strategy described in the next paragraph.

\section{Stimulation Strategies}

The primary stimulation strategy we used for the TetraTrike included 5 channels of stimulation per leg (10 channels total), provided by two Hasomed Rehastim 1 stimulators, one for each side of the body. Two channels were used for each quadricep group: one for vastus medialis and one for rectus femoris (Figure 5, left). The other three channels were used respectively for hamstrings, glutei, and back muscles. Back muscles were activated contra-laterally to the quadriceps, in order to rigidify the upper body and allow for better transmission of the forces to the pedal. We did not implement a closed-loop control strategy, and left it to the pilot to regulate the speed in relation to the perceived fatigue/endurance. For that purpose, the pilot used a joystick (Figure 2, lower lefthand side) to incrementally change the stimulation intensity in three discrete steps of $60 \%, 80 \%$ and $100 \%$ (i.e. $300 \mu$ s, $400 \mu \mathrm{s}$ and $500 \mu \mathrm{s}$ pulse width) of the maximum available intensity. In the later stages of our preparation for the competition, asynchronous distributed stimulation was studied in an effort to reduce muscle fatigue. ${ }^{19-21} \mathrm{We}$ used two Unafet stimulators to deliver 8 stimulation channels to each quadricep group (Figure 5, right). The initial results were promising when stimulating quadriceps only, however we did not have sufficient time to optimize the system before the competition. Consequently, we decided to avoid complications with synchronization and used the simpler configuration with two Hasomed Rehastim 1 stimulators for race day.

\section{Stimulation Patterns}

In order to determine an efficient stimulation pattern, we first used an electromyography (EMG) recording of the activity in five muscle groups (Rectus Femoris, Vastus Lateralis, Vastus Medialis, Hamstrings and Glutei) in two healthy subjects while riding the TetraTrike. The corresponding EMG recordings are shown on Figure 6. The derived stimulation pattern required an angle correction due to electromechanical delays in the system (cca. $30^{\circ}$ corresponding to cca. $100 \mathrm{~ms}$ at $40 \mathrm{rpm}$ ). However, when applying the derived stimulation pattern to tetraplegic pilots, it was impossible for them to overcome the "dead spot", even with the TetraTrike in a fixed gear configuration. We assume this difference arises from substantial use of the hip flexors by the healthy subjects, which were not accessible through our transcutaneous stimulation. We thus proceeded to use stimulation patterns that can be found in the literature to develop "base" stimulation patterns that were further optimized by trial and error for each pilot. For each pilot, seven different stimulation patterns were tested prior to any optimization. The first five were taken from BerkelBike software documentation and the last two from the work of Dr. Kenneth Hunt. ${ }^{22}$ These patterns are presented in Table 3. As the Hasomed stimulator only allowed tuning angles in discrete 10 degree increments, the latter were rounded to the closest multiple of 10 . For triggering the back muscles, we simply stimulated them with a phase lag of $180^{\circ}$ with respect to the quadriceps muscles to achieve contra-lateral timing between the two muscle groups. After testing all the patterns, the one providing the best timing over $100 \mathrm{~m}$ was chosen, and then empirically improved using the subjective feeling of pedaling smoothness of the pilot. The final patterns for the two pilots training for the Cybathlon are presented in Figure 7. Their patterns are compared in the figure to the EMG recording from a healthy patient, and to the TUM minimum pattern found in the BerkelBike documentation. The stimulation angles represent the position of the pedals with the 0 -angle defined when the crank arm is horizontal with the right leg fully flexed. The colored sections correspond to the angles where the muscles are stimulated from initiation to completion of the stimulation period.

\section{Performance achieved at Cybathlon}

The ENS de Lyon team competed in the very first leg of the FES cycling competition. Unfortunately, during the first lap of the race the drive chain on the trike derailed. This occurred because two screws securing the boom of the trike were not sufficiently tightened. The situation was further exaggerated by the rough surface and bumps present on the race track. The vibrations during the ride 
loosened the boom which relaxed the chain allowing it to derail. Since we had to put the chain back on the trike, the team was automatically disqualified. Before the chain derailed, we had completed $75 \mathrm{~m}$ in $29 \mathrm{~s}(9.3$ $\mathrm{km} / \mathrm{h}$ ). We know that the best timing recorded during training was $6 \mathrm{~min} 15 \mathrm{sec}$ for $750 \mathrm{~m}(7.2 \mathrm{~km} / \mathrm{h})$, and $1 \mathrm{~min}$ $22 \mathrm{sec}$ for $250 \mathrm{~m}(10.9 \mathrm{~km} / \mathrm{h})$. This is to be compared to the best timing for a non-implanted pilot at Cybathlon, which was 750 meters in $3 \mathrm{~m} 59 \mathrm{~s}(11.3 \mathrm{~km} / \mathrm{h})$.

\section{Discussion}

Switching from a freewheel to a fixed-gear strategy allowed us to achieve smooth pedaling and overcome the "dead spot" position in the pedal stroke. Due to spasticity issues, our back-up pilot never achieved a fluid cyclic pedaling movement until we switched to the fixed-gear configuration. Although no quantitative measurements were taken, we witnessed a substantial increase in the leg muscle volume (thigh size) of the pilots over the training period, suggesting an improvement of muscle trophicity. However, we also noted that the observed muscle size increase was lost over a two-week period after training was stopped. Of special note, for the first time since his 2013 accident our primary pilot partially recovered his ability to transpire in his neck and back, up to the mid-thoracic level. We observed this midway through the training in the spring of 2016 during one training session. This suggests partial recovery of the sympathetic nervous system. Whether this is directly due to the intense FES cycling training we cannot definitively conclude, but this new function continues even after training has been discontinued and the observation should be followed up in future studies. Furthermore, leg spasticity reduction was also observed, which is currently under investigation. ${ }^{6,23}$ Muscle fatigue issues should also be further explored with multi-site stimulation strategies using asynchronous distributed stimulation, and/or stochastic distribution of pulse frequency, width and intensity. Lastly, the mechanical power output has to be further quantified in order to improve stimulation patterns and strategies in a reproducible manner, ideally by providing systematic procedures that optimize cycling performance for each pilot. ${ }^{24,25}$ Exchange of information with other teams present at the first Cybathlon FES Cycling competition will provide further hints and tips. ${ }^{26-32}$

\section{List of acronyms}

EMG - Elettromyography

FES - Functional Electrical Stimulation

SCI - Spinal Cord Injury

\section{Author's contributions}

All the authors of the present manuscript were substantially involved in team ENS de Lyon preparations for the 2016 Cybathlon games. AM led aspects regarding mechanical conception, while electronic design and firmware was under the direction of LP-M; SM headed details regarding physical preparation of the FES cycling pilots, and was assisted by LL, who assumed responsibility for daily training sessions and data collection. VB was responsible for supervision of the team and was also the primary pilot for the team's FES cycling competition.

\section{Acknowledgments}

The authors would like to acknowledge for their significant contributions: Professor Dejan Popović for his expertise and counseling concerning functional electrical stimulation; Denis Le Tourneau for his help during mechanical conception and construction of key elements used to modify our FES competition tricycle; Julien Jouffroy and Michel Sorine for volunteering as pilots and training for the competition; Amandine Matera and Rhône Orthopédie for the production of several pairs of carbon-fiber foot orthoses. Fundings: ENS de Lyon, CNRS, the not-for-profit association ANTS, and the grant III44008 from the Ministry of Education, Science and Technological Development of Serbia funded this work

\section{Conflict of Interest}

The authors declare that there is no conflict of interest.

\section{Ethical Publication Statement}

We confirm that we have read the Journal's position on issues involved in ethical publication and affirm that this report is consistent with those guidelines.

\section{Corresponding Author}

Amine Metani, ENS de Lyon - Laboratoire de Physique 46 allée d'Italie - 69007 Lyon, France.

E-mail: amine.metani@protonmail.ch

E-mails of co-authors

Lana Popović-Maneski: lanapm13@gmail.com

Sebastien Mateo: laura.lemahieu@ens-lyon.fr

Laura Lemahieu: sebastien.mateo@gmail.com

Vance Bergeron: vance.bergeron@ens-lyon.fr

\section{References}

1. Cybathlon website, http://www.cybathlon.ethz.ch/

2. Popović DB. Advances in functional electrical stimulation (FES). J Electromyogr Kinesiol 2014;24:795-802.

3. Guimarães JA, da Fonseca LO, Dos Santos-CoutoPaz CC, et al. Towards parameters and protocols to recommend FES-cycling in cases of paraplegia: a preliminary report. Eur J Transl Myol 2016;26:6085

4. Peri E, Ambrosini E, Pedrocci A, et al. Can FESaugmented active cycling training improve locomotion in post-acute elderly stroke patients? Eur J Transl Myol 2016;26:6063.

5. Frotzler A, Coupaud S, Perret C, et al. Highvolume FES-cycling partially reverses bone loss in 
people with chronic spinal cord injury. Bone 2008;43(1):169-76.

6. Popović Maneski L, Aleksić A, Metani A, et al. Retrospective analysis of the effects of FES induced intensive motor activity in spasticity in subjects with spinal cord injury: Use it or lose it! Trans on Neural Systems \& Rehabilitation Engineering 2017; under review.

7. Crameri RM, Weston A, Climstein M, et al. Effects of electrical stimulation-induced leg training on skeletal muscle adaptability in spinal cord injury. Scand J Med Sci Sports 2002;12:316-22.

8. Griffin L, Decker MJ, Hwang JY, et al. Functional electrical stimulation cycling improves body composition, metabolic and neural factors in persons with spinal cord injury. J Electromyogr Kinesiol 2009;19:614-22.

9. Hunt KJ, Fang J, Saengsuwan J, et al. On the efficiency of FES cycling: a framework and systematic review. Technol. Health Care 2012;20:395-422.

10. Feiereisen P, Duchateau J, Hainaut K. Motor unit recruitment order during voluntary and electrically induced contractions in the tibialis anterior. Exp Brain Res 1997;114:117-23.

11. Popovic D, Sinkjær T. Control of Movement for the Physically Disabled: Control for Rehabilitation Technology. Springer; 2000.

12. Berkel Bike website, http://berkelbike.com/ product/berkelbike-pro/ (2017, accessed 26 September 2017).

13. Papachristos A. Functional Electrical Stimulation in Paraplegia, Topics in Paraplegia, PhD 2014. Yannis Dionyssiotis (Ed.), InTech.

14. Carbontrikes website, http://www.carbontrikes .com/eng/models.html (2017, accessed 28 September 2017).

15. ScienceStim real-time Hasomed Rehastim interface, http://sciencestim.sourceforge.net/ dokuwiki/doku.php?id=rehastim1 (2017, accessed 28 August 2017).

16. Osymetric website, https://www.osymetric. com/fr/, (2014, accessed 28 September 2017).

17. Szecsi J, Krause P, Krafczyk S, et al. Functional output improvement in FES cycling by means of forced smooth pedaling. Med Sci Sports Exerc 2007;39:764-80.

18. Miler V, Bijelić G, Schwirtlich L. Neural prosthesis for the therapy of low back pain. J Autom Control 2008;18:93-7.

19. Popović L, Malešević NM. Muscle Fatigue of Quadriceps in Paraplegics: Comparison between Single vs. Multi-pad Electrode Surface Stimulation. Proc of IEEE EMBC, Minneapolis, MN, 2009;6785-8.

20. Malešević NM, Popović LZ, Schwirtlich L, Popovic DB. Distributed low-frequency functional electrical stimulation delays muscle fatigue compared to conventional stimulation, Muscle Nerve 2010;42:556-62.

21. Popović-Maneski LZ, Malešević NM, Savić A, et al. Surface distributed low-frequency asynchronous stimulation delays fatigue of stimulated muscles. Muscle Nerve 2013;48:930-7.

22. Hunt KJ, Ferrario C, Grant S, et al. Comparison of stimulation patterns for FES-cycling using measures of oxygen cost and stimulation cost. Med Eng Phys 2006;28:710-8.

23. Popović-Maneski L, Aleksić A, Metani A, et al. Assessment of spasticity by a pendulum test in SCI patients who exercise FES cycling or receive only conventional therapy. TNSRE 2017 , in process of publishing, DOI: 10.1109/TNSRE.2017.2771466

24. Popović-Maneski L, Metani A, Le Jeune F, Bergeron V. A systematic method to determine customised FES cycling patterns and assess their efficiency. Proc. 4th Intern. Conf. Electrical, Electronics and Computing Engineering, IcETRAN 2017, Kladovo, Serbia. pp.BTI2.3.1-4

25. Popovic-Maneski L, Metani A, Bergeron V, Popovic DB. Assessing different muscle contributions during FES cycling. Proc of IFESS 2017, London, UK, pp.28

26. Azevedo Coste C, Bergeron V, Berkelman R, et al. Comparison of strategies and performance of functional electrical stimulation cycling in spinal cord injury pilots for competition in the first ever Cybathlon. Eur J Transl Myol 2017;27:251-4.

27. Berkelmans R, Woods B. Strategies and performances of Functional Electrical Stimulation Cycling using the BerkelBike with Spinal Cord Injury in a competition context (CYBATHLON). Eur J Transl Myol 2017;27:255-258.

28. Laubacher M, Aksöz EA, Bersch I, Hunt KJ. The road to Cybathlon 2016 - Functional electrical stimulation cycling Team IRPT/SPZ. Eur J Transl Myol 2017;27:259-264.

29. Sijobert B, Fattal C, Daubigney A, AzevedoCoste B. Participation to the first Cybathlon: an overview of the FREEWHEELS team FES-cycling solution. Eur J Transl Myol 2017;27:265-2.

30. Guimarães JA, Oliveira da Fonseca L, de Sousa AC, et al. FES Bike Race preparation to Cybathlon 2016 by EMA team: a short case report. Eur J Transl Myol 2017;27:272-78.

31. McDaniel J, Lombardo LM, Foglyano KM, et al. Cycle Training Using Implanted Neural Prostheses: Team Cleveland. Eur J Transl Myol 2017;27:289-94.

32. Arnin J, Yamsa-ard T, Triponyuwasin P, Wongsawat Y. Development of practical functional electrical stimulation cycling systems based on an electromyography study of the Cybathlon 2016. Eur J Transl Myol 2017;27:295-301. 